\title{
Morphological and physiological factors involved in the contractility of the spermatic cord and ductus deferens of the opossum (Didelphis albiventris)
}

\author{
C. R. S. Machado, S. L. Calixto* and W. Ladosky* \\ *Department of Physiology and Pharmacology, Universidade Federal de Pernambuco, \\ Recife, 50.000-Pernambuco, and Department of Morphology, Universidade Federal de Minas \\ Gerais, Belo Horizonte, 30.000-Minas Gerais, Brasil
}

\begin{abstract}
Summary. The opossum spermatic cord is characterized by a thick skeletal muscle coat, provided by the great development of the cremasteric muscle. Acetylcholine induced a powerful contraction of the spermatic cord placed in an organ bath containing Heller's solution. This contraction was blocked by curare but not completely by atropine as is usual for skeletal muscle. However, the ductus deferens did not respond to acetylcholine or catecholamines under the same conditions.

Specific histochemical methods for both catecholamines and acetylcholinesterases revealed that the ductus deferens musculature, composed mainly of circular fibres, is richly innervated by adrenergic and presumed cholinergic nerve fibres. The lack of responsiveness to the neurotransmitters could be explained by the absence of longitudinally arranged muscle. It is suggested that in the opossum the cremaster could participate in the mechanism of sperm transport.
\end{abstract}

\section{Introduction}

The spermatic cord of marsupials has been well studied regarding its characteristic rete mirabile and its pampiniform plexus of veins (Harrison, 1949; Barnett \& Brazenor, 1958; Godinho, Cardoso \& Nogueira, 1977). Barnett \& Brazenor (1958) referred also to the thick cremasteric coat found in the cord of most marsupials. Indeed, one of the most remarkable features of the opossum spermatic cord is the great development of the cremaster muscle which almost completely embraces the other components of the cord (Nogueira, Godinho \& Cardoso, 1977). However, the ductus deferens of marsupials has not been studied in detail by morphological or physiological methods. As far as we know, only the duct epithelium has been described for the opossum (Chase, 1939). However, the opossum ductus deferens certainly deserves more attention, not only for evolutionary reasons but also because of the possibility that it might be involved in the phenomenon of spermatorrhoea that occurs in marsupials (Biggers, 1966).

We have therefore studied the anatomy and some physiological properties of the spermatic cord and ductus deferens of the South American opossum, Didelphis albiventris.

\section{Materials and Methods}

The animals were white-eared South American opossums Didelphis albiventris (formerly known as Didelphis azarae; see Hershkovitz, 1969). Opossums belong to the marsupial family Didelphidae and are usually regarded as one of the oldest living mammals (Tyndale-Biscoe, 
1973). Mature adult animals, weighing 750-1000 g, were captured in the vicinities of Belo Horizonte and Recife, Brazil. They were maintained in the laboratory for periods of 6-30 days. Food consisted of fruit, vegetables, chickens and beef meat. Water was always available.

\section{Histological and histochemical methods}

Six animals were killed under ether anaesthesia and the spermatic cord was dissected out by cutting the testicular and inguinal ends. Fragments taken from the proximal, middle and distal portions of the organ were used for the histological and histochemical studies.

For the histological studies the tissues were fixed in Bouin's fluid and embedded in paraffin wax. The sections were cut at $5 \mu \mathrm{m}$ and stained by haematoxylin and eosin or by Gomori's trichrome methods. For the demonstration of adrenergic innervation, cryostat sections $32 \mu \mathrm{m}$ thick were processed for the histochemical demonstration of catecholamines by the highly specific glyoxylic acid-induced fluorescence method, according to de la Torre \& Surgeon (1976). The sections were quickly dipped 3 times at room temperature in a solution of sucrose $(0.2 \mathrm{M})$, monobasic potassium phosphate $(0.236 \mathrm{M})$, and $1 \%(\mathrm{w} / \mathrm{v})$ glyoxylic acid monohydride (Sigma). Excess fluid was removed and the slides were dried under an air dryer for 5-10 min. The dried sections were then placed in the oven at $80^{\circ} \mathrm{C}$ for $5 \mathrm{~min}$. The sections were covered with mineral oil and coverslips, and placed for $90 \mathrm{sec}$ on a hot plate at $80^{\circ} \mathrm{C}$. The sections were then examined with a fluorescence microscope (Orthoplan) equipped with Ploemopak 2.1.

For the histochemical study of cholinergic (acetylcholinesterase-containing) nerve fibres the tissues from 4 animals were fixed in $10 \%(\mathrm{v} / \mathrm{v})$ formalin containing $1 \%(\mathrm{w} / \mathrm{v})$ calcium chloride for $12 \mathrm{~h}$ at $0-4^{\circ} \mathrm{C}$, soaked for $6-8 \mathrm{~h}$ in gum-sucrose $(0.88 \mathrm{M}$-sucrose and $1 \%(\mathrm{w} / \mathrm{v})$ gum) at $0-4^{\circ} \mathrm{C}$ and then washed in ice-cold distilled water for $0.5 \mathrm{~h}$. Cryostat sections $(16 \mu \mathrm{m})$ were then treated according to the thiocholine method of Karnovsky \& Roots (1964) for cholinesterases. The incubation media also contained 1.6 $\mu \mathrm{M}$ isoOMPA (Sigma) which ensures inhibition of non-specific cholinesterases. Some slides were incubated in the medium without the substrate (acetylthiocholine iodide) as control.

\section{Ductus deferens preparation}

The cephalic third of the cord was dissected out and cleaned of adjoining connective tissues and immediately transferred to a Petri dish containing Heller's solution at $30^{\circ} \mathrm{C}$. For experiments with the spermatic cord, the tissue was immediately transferred to a $10 \mathrm{ml}$ organ bath containing Heller's solution maintained at $30^{\circ} \mathrm{C}$. This fluid is suitable for maintaining a regular and constant contraction during a long period of time (Heller, 1973). For the ductus deferens studies the spermatic cord was opened with forceps by pulling out a fat line which appears along one side. The ductus deferens was then freed from the vascular connective tissue which formed the funiculum and was transferred to the organ bath.

Muscular contractions of the tissues were recorded on a smoked drum with an isotonic frontal lever (Kavanagh, 1962) at loads of $1 \mathrm{~g}$ and at a magnification of 6 times.

Some animals were injected subcutaneously with reserpine dissolved in distilled water (5 $\mathrm{mg} / \mathrm{ml})$ at 48 and $24 \mathrm{~h}(1 \mathrm{mg} / \mathrm{kg})$ and $12 \mathrm{~h}(5 \mathrm{mg} / \mathrm{kg})$ before being killed.

\section{Histology}

\section{Results}

The spermatic cord is very thick and coloured reddish except along a thin ventro-medial white line which broadens at the inguinal end. This appearance is due to the presence of a well developed cremaster muscle which surrounds the other cord components, except along the white 
ventro-medial line (Pl. 1, Fig. 1) which contained adipose tissue. The cremasteric muscle fibres were disposed longitudinally and the cremaster muscle constituted a striated muscular tube which contained the spermatic artery or its branches (the rete mirabile which has been studied by Godinho et al., 1977), the pampiniform plexus of veins, the nerves of the spermatic plexus, lymphatic vessels, and the ductus deferens. These elements were ensheathed together in connective tissue and were delimited by a fibrous band homologous to the internal spermatic fascia of man (Shafik, 1977). Between this fibrous band and the cremaster muscle, and along the ductus deferens, a variable amount of adipose tissue was found. This adipose tissue was more abundant at the inguinal end of the cord but gradually diminished toward the testicular end where it was practically absent (Pl. 1, Fig. 1).

The ductus deferens (Pl. 1, Fig. 2) was lined with pseudostratified epithelium similar to that of eutherian mammals. Its musculature, however, was delicate, consisting of only one layer of smooth muscle fibres, disposed mainly circularly, intermingled with some collagenous fibres and fibrocytes. The adventitia of the dense connective tissue was relatively thick and contained blood vessels. No histological differences were observed along the length of the ductus deferens.

\section{Adrenergic and cholinergic innervation}

The glyoxylic acid method for demonstration of catecholamine-containing nerves showed a rich network of varicose fluorescent terminals throughout the muscular layer of the ductus deferens (Pl. 1, Fig. 3). A few thin nerve bundles were also seen running in the adventitia. The arteries of the rete mirabile and of the cremasteric muscle were poorly innervated and the other elements of the spermatic cord were devoid of fluorescent nerve fibres. The distribution of fluorescent nerve fibres in the proximal, middle and distal regions of the spermatic cord was similar.

The technique used for localizing acetylcholinesterase (AChE) activity in the spermatic cord revealed a cholinergic innervation only on the ductus deferens. Along the whole length of the ductus deferens, AChE-containing nerve fibres organized in fine bundles or apparently as single varicose fibres formed a network in the muscular layer (Pl. 1, Fig. 4). Some fibres were also observed in the outer part of the adventitia.

\section{Physiological studies on the spermatic cord}

The addition of acetylcholine to the organ bath, at a final concentration of $3 \times 10^{-8} \mathrm{M}$, resulted in an immediate contraction as shown in Text-fig. 1(a). A dose of $10^{-8} \mathrm{M}$ resulted in an increase only in spontaneous low-frequency contractions. An augmentation of the contractile response was observed as concentration increased further, demonstrating a dose-response relationship. The maximum response was observed with $3 \times 10^{-5} \mathrm{M}$ (results for higher doses not shown), the $\mathrm{ED}_{50}$ corresponding to $1.4 \times 10^{6} \mathrm{M}$. When atropine at $10^{-6} \mathrm{M}$ was added to the bath the dose-response curve of acetylcholine was moved to the right (Text-fig. 1a). When the response with $10^{-6} \mathrm{M}$ acetylcholine was considered as the $100 \%$ response, addition of atropine in progressive doses reduced the contractile response only to $75 \%$ of the initial value (Text-fig. $1 \mathrm{~b}$ ). When curare at $10^{-5} \mathrm{M}$ was added to the bath the dose-response curve to acetylcholine was shifted to the right, indicating a competitive blockage (Text-fig. 1c). At a dose of $10^{-4} \mathrm{M}$, curare blocked completely the acetylcholine-sensitive contractile activity of the spermatic cord.

Neither adrenaline nor noradrenaline at doses ranging from $10^{-7}$ to $10^{-3} \mathrm{M}$ induced any measurable contractile response of the spermatic cord. After a contraction induced by $10^{-6}$ M-acetylcholine, addition of adrenaline or noradrenaline to the bath did not induce any relaxation.

Barium chloride $\left(10^{-3} \mathrm{M}\right)$ added to the bath containing the spermatic cord induced a 

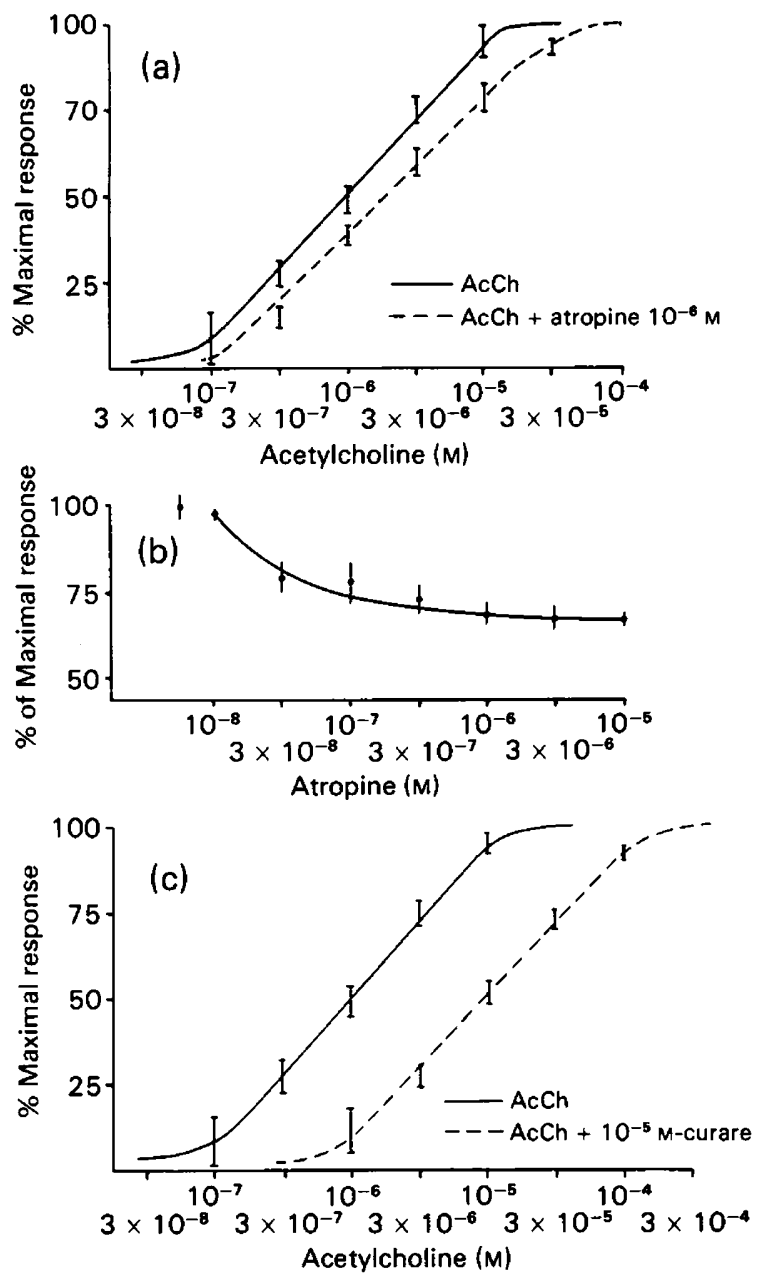

Text-fig. 1. The contractile response of the opossum spermatic cord to various substances. (a) Acetylcholine and atropine which induces a competitive blockage. (b) Effect of atropine with a constant dose $\left(10^{-6} \mathrm{M}\right)$ of acetylcholine. (c) Addition of curare altered the dose-response curve to the right, indicating the competitive mechanism of the blockage. Each point represents the mean \pm s.e.m. for 6 animals (12 ducts).

\section{PLATE 1}

Fig. 1. Transverse section through the distal third of the opossum spermatic cord. Note the thick coat provided by the cremaster muscle $(\mathrm{cm})$. The ductus deferens $(\mathrm{d})$ and vessels are ensheathed by connective tissue delimited by a fibrous band (f). Haematoxylin and eosin. $\times 35$.

Fig. 2. The ductus deferens of the opossum showing the smooth muscle fibres disposed mainly circularly. Haematoxylin and eosin. $\times 220$.

Fig. 3. Fluorescence photomicrograph of the opossum ductus deferens showing the rich network of adrenergic varicose fibres in the musculature. Some poorly innervated arterioles are present (arrows). Glyoxylic acid treatment. $\times 112$.

Fig. 4. The ductus deferens of the opossum showing the rich network of acetylcholinesterase-active nerve fibres in the muscular layer. Karnovsky \& Roots (1964) method. $\times 112$. 
PLATE 1
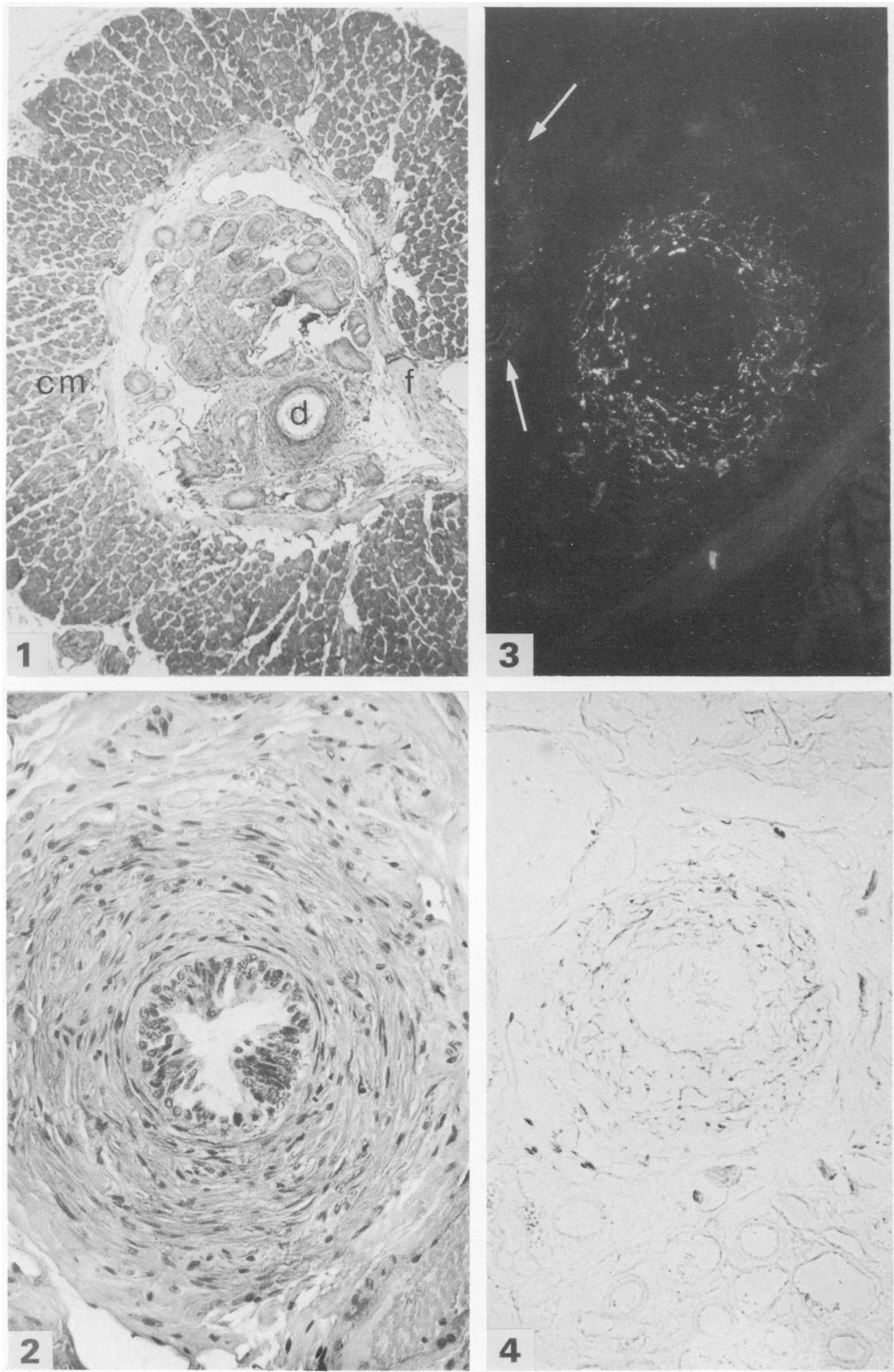
sustained contraction which lasted for about $45 \mathrm{~min}$, followed by very slow relaxation which lasted up to $90 \mathrm{~min}$. Continued washing did not accelerate the process of the relaxation.

\section{Physiological studies on the ductus deferens}

Contrary to the results for the spermatic cord, acetylcholine did not induce any contractile response in the ductus deferens, and there was no effect after addition of noradrenaline or adrenaline to the bath. Noradrenaline at doses of $10^{-6}, 10^{-5}$ and $10^{-4} \mathrm{M}$ added to the bath 30 min after the addition of $10^{-7} \mathrm{M}$-cocaine did not induce any contractile response. Noradrenaline added to the bath containing the ductus deferens of a previously reserpinized opossum did not induce any contractile response. Barium chloride induced a very weak contraction of the ductus deferens when added to the bath at a dose of $10^{-3} \mathrm{M}$.

\section{Discussion}

The mechanical response found in the spermatic cord of this opossum is compatible with its thick cremasteric coat, described by Nogueira et al. (1977). Therefore, the cord responds like skeletal muscle to acetylcholine and this response is blocked by curare, but not by atropine. As expected, it does not respond to any dose of catecholamines, since the cremaster is a pure striated skeletal muscle in which adrenergic fibres are related exclusively to vessels.

The histological preparations show that the ductus of the opossum is very different from that of eutherian mammals in the arrangement of its muscular layer. Instead of a thin inner longitudinal layer, a rather thick middle circular layer and an outer longitudinal layer, the opossum ductus deferens presents only one layer of predominantly circular smooth muscle fibres. In this respect it resembles the ductus deferens of reptiles (Patt \& Patt, 1969) and of birds (Patt \& Patt, 1969; Tingari, 1971). Our histochemical data showed that this rather delicate musculature is well innervated by $\mathrm{AChE}$-positive and adrenergic fibres, as is usual for eutherian mammals (Risley \& Skrepetos, 1964; Sjostrand, 1965; Shirai, Sasaki \& Rikimaru, 1973).

In spite of its presumably cholinergic innervation, the opossum ductus deferens does not respond to acetylcholine in doses of up to $10^{-4} \mathrm{M}$. However, very high pharmacological doses of acetylcholine elicit measurable contraction. Catecholamines in doses of up to $10^{-4} \mathrm{M}$ also failed to contract the opossum ductus deferens, in spite of its rich adrenergic innervation.

Wakade \& Krusz (1972) suggested that in the ductus deferens of the guinea-pig the uptake of noradrenaline is so fast that the contractile response does not appear after exogenous noradrenaline addition to the bath. This is not the case, however, for the opossum because cocaine does not facilitate any response to noradrenaline. Wadsworth (1973) states that the dense adrenergic innervation of the guinea-pig ductus deferens may account for its lack of sensitivity to noradrenaline, since it appears after pharmacological denervation with 6hydroxydopamine or reserpinization. However, reserpinization did not induce any response to exogenous noradrenaline in the opossum ductus deferens.

Our results suggest that the ductus deferens in the opossum is not an important contractile structure, at least with the methods herein used. The fact that barium chloride, a substance which contracts muscle independently of membrane receptors evokes shortening of the spermatic cord but has almost no effect on the isolated ductus deferens reinforces this suggestion.

This lack of responsiveness to acetylcholine and catecholamines in the presence of cholinergic and adrenergic innervation could be explained by our histological data on the musculature of the opossum ductus deferens. Indeed, the physiological tests used were appropriate to measure the contraction of longitudinally arranged muscle but this is not apparent in opossum ductus deferens. There remains, however, the possibility that the circular 
layer which constitutes the musculature of the opossum ductus deferens may be contracted under acetylcholine and catecholamine stimulations, producing peristaltic waves. More suitable preparations for studying the contraction of circular muscle would be required to examine this possibility.

The morphological and physiological characteristics of the opossum ductus deferens raise the possibility that, in this animal, the cremaster might be involved in the transport of spermatozoa. At least in man this muscle, through its sphincteric action on the cord veins, plays an important role in the thermoregulatory mechanism of the testes (Shafik, 1973). In the opossum, besides having a similar role in the powerful contraction of the cremaster which causes a great shortening of the whole cord, it might have a propulsive action on the spermatozoa. When performed independently of sexual activity the contraction could possibly explain the spermatorrhoea reported in marsupials. In our animals numerous spermatozoa were seen in sediments of centrifuged urine, obtained under anaesthesia, from the urinary bladder. The fact that the cremasteric coat is firmly applied to the dense connective tisue (fibrous band and connective tissue among the vessel) along the distal half of the spermatic cord with almost no adipose tissue intermingled reinforces the suggestion of such a pump function for the striated muscle.

Further research is required to elucidate the mechanism of sperm transport in the opossum.

This paper was supported by grants from the Brazilian Research Council (CNPq) and FINEP.

\section{References}

Barnett, C.H. \& Brazenor, C.W. (1958) The testicular rete mirabilis of marsupials. Aust. J. Zool. 6, 27-32.

Biggers, J.D. (1966) Reproduction in male marsupials. Symp. zool. Soc. Lond. 15, 251-280.

Chase, E.B. (1939) The reproduction system of the male opossum, Didelphis virginiana Kerr and its experimental modification. J. Morph. 65, 215-239.

de La Torre, J.C. \& Surgeon, J.W. (1976) A methodological approach to rapid and sensitive monoamine histofluorescence using a modified glyoxylic acid technique: the SPG method. Histochemistry 49, 81-93.

Godinho, H.P., Cardoso, F.M. \& Nogueira, J.C. (1977) Blood supply to the testis of a Brazilian marsupial (Didelphis azarae) and its abdomino-testicular temperature gradient. Acta anat. 99, 204-208.

Harrison, R.G. (1949) The comparative anatomy of the blood supply of the mammalian testis. Proc. zool. Soc. Lond. 119, 325-343.

Heller, H. (1973) The effects of oxytocin and vasopressin during the oestrous cycle and pregnancy on the uterus of a marsupial species, the Quokka (Setonix brachyurus). J. Endocr. 58, 657-671.

Hershkovitz, P. (1969) The evolution of mammals on Southern Continents. VI. The recent mammals of the neotropical region: A zoogeographic and ecological review. Q. Rev. Biol. 44, 1-70.

Karnovsky, M.J. \& Roots, L. (1964) A direct coloring thiocholine method for cholinesterases. J. Histochem. Cytochem. 12, 219-221.

Kavanagh, L. (1962) A light writing-point pivoted on watch-bearings for frontal levers. J. Physiol., Lond. 162, $1 p-2 p$.

Nogueira, J.C., Godinho, H.P. \& Cardoso, F.M. (1977)
Microscopic anatomy of the scrotum, testis with its excurrent duct system and spermatic cord of Didelphis azarae. Acta anat. 99, 209-219.

Patt, D.I. \& Patt, G.R. (1969) Comparative Vertebrate Histology, p. 292. Harper \& Row, New York.

Risley, P.L. \& Skrepetos, C.N. (1964) Histochemical distribution of cholinesterases in the testis, epididymis and vas deferens of the rat. Anat. Rec. 148, 231-249.

Shafik, A. (1973) The cremasteric muscle. Role in varicocelogenesis and in thermoregulatory function of the testicle. Invest. Urol. 11, 92-97.

Shafik, A. (1977) Cremasteric muscle. In The Testis, pp. 481-489. Eds A. D. Johnson \& W. R. Gomes. Academic Press, New York.

Shirai, M., Sasaki, K. \& Rikimaru, A. (1973) A histochemical investigation of the distribution of adrenergic and cholinergic nerves in the human male genital organ. Tohoku J. exp. Med. 111, 281-291.

Sjostrand, N.O. (1965) The adrenergic innervation of the vas deferens and the acessory male genital glands. Acta physiol. scand. 65, Suppl. 257, 1-82.

Tingari, M.D. (1971) On the structure of the epididymal region and ductus deferens of the domestic fowl (Gallus domesticus). J. Anat. 109, 423-435.

Tyndale-Biscoe, C.H. (1973) Life of Marsupials. Edward Arnold. London.

Wadsworth, R.M. (1973) Abolition of neurally evoked motor response of the vas deferens by 6-hydroxydopamine. Eur.J. Pharmac. 21, 383-387.

Wakade, A.R. \& Krusz, J. (1972) Effect of reserpine, phenoxybenzamine and cocaine on neuromuscular transmission in the vas deferens of the guinea-pig. $J$. Pharmac. exp. Ther. 181, 310-317. 